\title{
Innovadoras soluciones digitales para generar las nuevas tendencias de futuro en el sector cerámico
}

\author{
GRUPO TORRECID
}

\begin{abstract}
Este producto obtuvo uno de los premios Alfa de Oro concedidos por la Sociedad Española de Cerámica y Vidrio en CEVISAMA 2013
\end{abstract}

En la presente nota técnica se recoge los aspectos más significativos del trabajo "Innovadoras soluciones digitales para generar las nuevas tendencias de futuro en el sector cerámico" por el que el Grupo Torrecid obtuvo el Premio Alfa de Oro 2013 otorgado por la Sociedad Española de Cerámica y Vidrio. Para conseguir los objetivos planteados ha sido necesario trabajar en diferentes campos de actuación para cada esmalte y tinta en concreto, abarcando, entre otros, aspectos como el desarrollo de fritas especiales, la selección de los disolventes más adecuados o la optimización de las composiciones para conseguir que las tintas tuvieran un comportamiento adecuado en el proceso de impresión y cumplieran todos los requisitos de estabilidad y calidad que el sector cerámico demanda.

Palabras clave: baldosas cerámicas, digital, esmaltado, decoración, D.G.-CID, T.M.-CID, SMART-CID, DECAL-CID.

This technical note contains the most significant aspects of the work "Innovative digital solutions to create the new future trends in the ceramic industry" in which the Group Torrecid won the "Alfa de Oro 2012" given by the Spanish Society of Ceramics and Glass. To achieve the stated objectives to work in different fields of activity for each specific glaze and ink has been necessary, comprising, among other, aspects such as the development of special frits, selecting the most suitable solvents or optimizing the compositions to ensure that the inks have appropriate behaviour in the printing process and met all the requirements of stability and quality that the ceramic industry demand.

Keywords: ceramic tiles, digital, glazing, decoration, D.G.-CID, T.M.-CID, SMART-CID, DECAL-CID.

\section{INTRODUCCIÓN}

El Grupo Torrecid comenzó la investigación y el desarrollo de tintas pigmentadas para decoración digital a finales de los años 1990, disponiendo de un completo conjunto de tintas en el año 2002 y siendo pionero en la implementación de la tecnología de decoración digital de baldosas cerámicas ${ }^{1,2}$ por inyección de tintas pigmentadas (INKCID ${ }^{\circledR}$ ) en el sector cerámico en el año 2004. Esta tecnología ha supuesto una verdadera revolución dentro del sector cerámico y, de hecho, su expansión a escala mundial ha tenido lugar a una gran rapidez, desbancando a otras técnicas de decoración como la serigrafía o la huecografía. Hoy en día hay más de 1.600 impresoras instaladas en todo el mundo, llegando a porcentajes de implantación de cerca del $80 \%$ en países como España o Italia o del 50\% en China, mientras que en las áreas geográficas que comenzaron más tarde a utilizar la tecnología, dicho porcentaje se encuentra entre el $10-15 \%$, por lo que todavía se prevé un crecimiento exponencial a lo largo de los próximos años.

Paralelamente, el Grupo Torrecid ha ido desarrollando otras tipologías de tintas para conseguir efectos decorativos no relacionados directamente con el color, introduciendo en el mercado en el año 2011 las tintas KERAMCID ${ }^{\circledR}$ y METALCID $^{\circledR}$, con las que se consiguen efectos cerámicos y metálicos respectivamente.
Sin embargo, todavía quedaban aspectos por resolver para poder ofrecer a los clientes una solución totalmente digital, en la que tanto el esmalte como la decoración fueran aplicados por tecnologías digitales, con todas las ventajas de producto, proceso y gestión que ello llevaría asociado. A su vez, también se detectaban ciertas lagunas en la decoración de productos cerámicos ya vitrificados, tanto en el caso de cerámica plana como en piezas con geometría compleja. Con todo ello se ve la necesidad de desarrollar un conjunto de innovadoras soluciones digitales con las que se pueda continuar generando las nuevas tendencias de futuro en el sector cerámico.

Estas soluciones digitales vienen a consolidar todavía más si cabe el liderazgo mundial en la venta de productos digitales que el GRUPO TORRECID ostenta desde el año 2004, liderazgo mundial que se sustenta también en la fiabilidad de las tintas que produce y en que ofrece al mercado la mejor gama cromática y la innovación con mayor valor añadido, sin olvidar su compromiso por la calidad y el servicio personalizado.

\section{OBJETIVO}

El Grupo Torrecid, siendo fiel a su estrategia de ser líderes mundiales en innovación para generar soluciones y tendencias 
de futuro con las que proporcionar a sus clientes las mejores ventajas competitivas y el mayor valor añadido y a la vista de las necesidades existentes comentadas en el apartado anterior, se planteó el objetivo de desarrollar las siguientes soluciones digitales:

- D.G-CID ${ }^{\circledR}$ : esmaltes digitales para la tecnología Drop-onDemand (DOD) de alta definición.

- $\quad$ T.M-CID ${ }^{\circledR}$ : esmaltes digitales para la tecnología Drop-onDemand (DOD) de alto gramaje.

- SMART-CID ${ }^{\oplus}$ : tintas digitales pigmentadas para la decoración de piezas cerámicas con superficies vitrificadas.

- DECAL-CID ${ }^{\circledR}$ : calcas digitales para la decoración de objetos cerámicos vitrificados de geometría compleja.

\section{DESARROLLO EXPERIMENTAL DE LAS SOLUCIONES DIGITALES}

Para conseguir los objetivos planteados ha sido necesario trabajar en diferentes campos de actuación para cada producto digital en concreto, abarcando, entre otros, aspectos como el desarrollo de fritas especiales, la selección de los disolventes más adecuados o la optimización de las composiciones para conseguir que los esmaltes y tintas digitales tuvieran un comportamiento adecuado en el proceso de impresión y cumplieran todos los requisitos de estabilidad y calidad que el sector cerámico demanda.

Estas cuatro innovaciones van a marcar un nuevo hito en la historia del sector cerámico ya que refuerzan su capacidad competitiva al optimizar el proceso productivo y ampliar las posibilidades creativas y decorativas de las baldosas cerámicas, lo que se traduce en una oferta más amplia de producto con un mayor valor añadido.

Es de destacar igualmente que, dada la Novedad Mundial de las soluciones digitales desarrolladas y la incidencia que van a tener en el sector cerámico en los próximos años, en todos los casos se ha procedido a la protección industrial de las mismas mediante las correspondientes patentes, a la vez que se han registrado las marcas D.G-CID ${ }^{\circledR}$, T.M-CID $^{\circledR}$, SMART-CID ${ }^{\circledR}$ y DECAL-CID ${ }^{\circledR}$.

\subsection{Esmaltes digitales: D.G.-CID ${ }^{\circledR}$ y T.M-CID ${ }^{\circledR}$}

Con los esmaltes digitales D.G-CID ${ }^{\circledR}$ y T.M-CID ${ }^{\circledR}$ el GRUPO TORRECID provoca un nuevo salto tecnológico presentando piezas $100 \%$ digitales, en las que tanto el esmalte como la decoración son aplicados mediante la tecnología de inyección. Con ello se aportan numerosas ventajas de producto, proceso y gestión que van a suponer una NUEVA REVOLUCIÓN en el sector cerámico. Entre otras muchas cabe destacar la reducción drástica de la longitud de la línea de esmaltado, pasando de los más de $150 \mathrm{~m}$ actuales a tan solo $15 \mathrm{~m}$; la facilidad y flexibilidad en el cambio y desarrollo de modelos o la mejora medioambiental al eliminar la generación de residuos. Además, la posibilidad de obtener acabados diferentes en una misma pieza o de esmaltar selectivamente las zonas altas y bajas del relieve, son otros de los aspectos que van a tener una especial trascendencia a la hora de ampliar las posibilidades creativas y adaptar la cerámica a los gustos de la moda actual y futura.

\section{D.G-CID ${ }^{\circledR}$ : ESMALTES DIGITALES PARA LA TECNOLOGÍA DROP-ON-DEMAND (DOD) DE ALTA DEFINICIÓN.}

Los esmaltes digitales D.G-CID ${ }^{\circledR}$ se han desarrollado para obtener productos cerámicos con capas de esmalte de espesor reducido y que además destacan por presentar una alta definición y calidad de imagen. Si bien con los esmaltes digitales D.G-CID ${ }^{\circledR}$ se puede abarcar toda la tipología de producto existente (porcelánico, monococción porosa, etc.), un caso particular de especial relevancia son las baldosas cerámicas de gran formato y fino espesor, las cuales están ganando rápidamente cuota de mercado ya que proporcionan nuevas soluciones arquitectónicas de gran aceptación por parte de prescriptores como arquitectos o interioristas. De hecho, con esta tipología de esmaltes digitales ya se han fabricado industrialmente baldosas de formato $3 \times 1 \mathrm{~m}$ y de tan solo $5 \mathrm{~mm}$ de espesor, las cuales a su vez han sido decoradas con las tintas digitales pigmentadas INKCID ${ }^{\circledR}$. La flexibilidad y adaptabilidad de estas grandes piezas aporta un valor añadido adicional a la cerámica dentro del mundo arquitectónico, ya que permite recubrir superficies curvas, conseguir suelos perfectamente planos sin la existencia de las conocidas "cejas" o generar fácilmente formatos personalizados.

Para su desarrollo ha sido necesario investigar nuevas familias de fritas que, con el tamaño nanométrico requerido por la tecnología DOD de alta definición, proporcionaran al mismo tiempo capas vítreas continuas y los acabados cerámicos deseados (brillo, mate, lustre ${ }^{3}$, etc.). A modo de ejemplo, en la siguiente figura se muestra el Difractograma de la frita ${ }^{4}$ desarrollada para el esmalte digital mate satinado, en el que se puede observar que desvitrifican las fases Diópsido, Cristobalita y Silicato de Circonio.

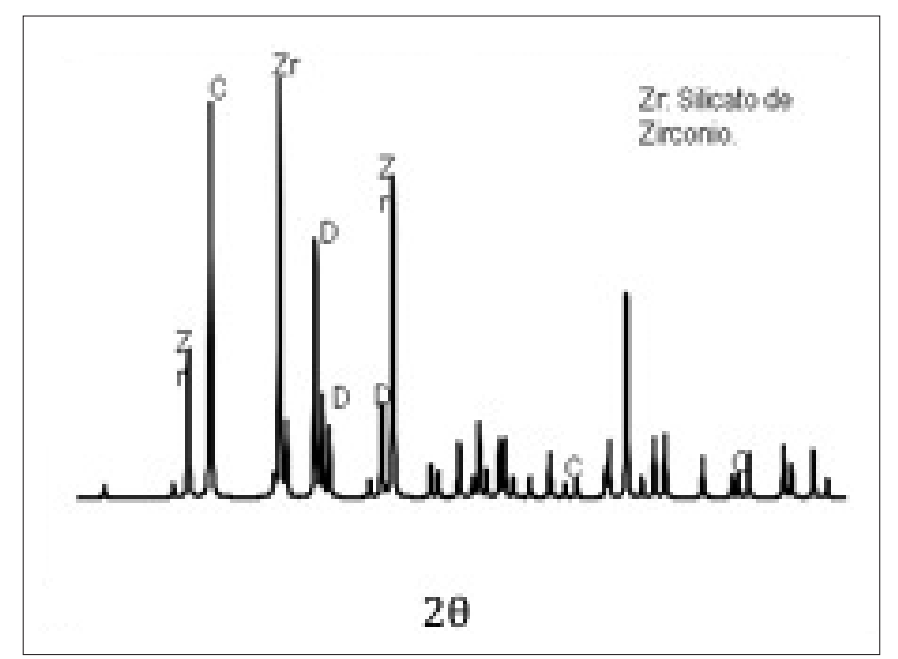

Figura 1. DRX de la frita del esmalte digital mate satinado.

Igualmente se tuvo que trabajar en la parte líquida de los esmaltes digitales, ensayando diferentes disolventes (hidrocarburos alifáticos, hidrocarburos aromáticos, glicoles, alcoholes, cetonas, etc.) y tipos de aditivos (dispersantes, ligantes, tensioactivos, humectantes, etc.) para conseguir unos esmaltes digitales que presentaran la estabilidad adecuada y cumplieran con los requisitos técnicos necesarios para garantizar un correcto comportamiento durante el proceso de impresión, tal como se observa en la figura 2, en la que se incluyen imágenes obtenidas con el equipo de 
visión de gota cuando se imprime con los esmaltes digitales desarrollados.

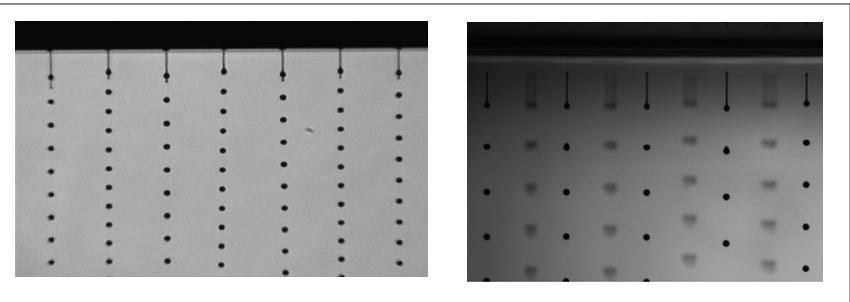

Figura 2. Imágenes de formación de gota de esmaltes digitales obtenidas con un equipo de visión de gota.

También es interesante destacar el diferente empaquetamiento de partículas que se consigue con los esmaltes D.G-CID ${ }^{\circledR}$, frente a los esmaltes tradicionales, lo que se observa claramente en la figura de Microscopía Electrónica siguiente y del que se derivan en gran medida las distintas propiedades que presentan.
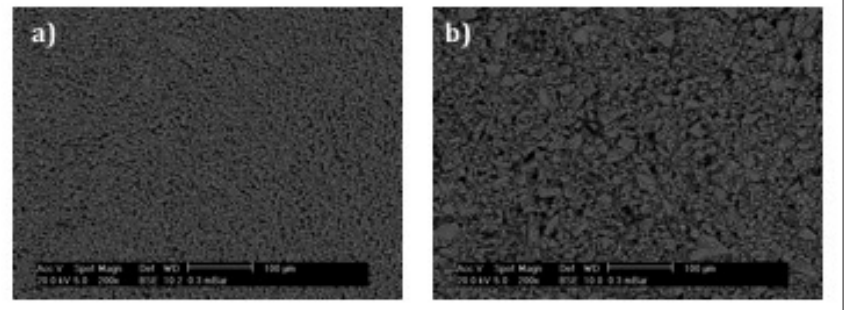

Figura 3. Imágenes de capas de esmalte obtenidas por MEB.

a) Esmalte digital. b) Esmalte tradicional.

\section{T.M-CID ${ }^{\circledR}:$ ESMALTES DIGITALES PARA LA TECNOLOGÍA DROP-ON-DEMAND (DOD) DE ALTO GRAMAJE}

Por su parte, los esmaltes digitales T.M-CID ${ }^{\circledR}$ están especialmente formulados para depositar capas de esmalte de espesor similar al que se consigue con las técnicas de esmaltado tradicional y en los que las exigencias en cuanto a la definición del diseño son menores que en el caso de los esmaltes D.G-CID ${ }^{\circledR}$, abarcando igualmente productos de monocción porosa, porcelánico, bicocción, etc. Para ello se utiliza una tecnología de esmaltado digital que se encuentra en fase de desarrollo y que sin duda también va a introducir cambios muy importantes en el proceso de fabricación cerámico.

El trabajo realizado en este caso se centró fundamentalmente en superar los condicionantes propios de la tecnología y que se resumen en los siguientes puntos:

- Resecado de los cabezales cuando se realiza una impresión en continuo.

- Salpicado durante el esmaltado digital.

- Formación de grietas de secado en el esmalte digital depositado.

- Presencia de numerosas burbujas en el esmalte digital en el momento de la aplicación.

- Sedimentación de partículas debida a la baja viscosidad requerida de los esmaltes digitales.

Para ello se trabajó principalmente en la utilización de disolventes adicionales al agua que era el disolvente principal, el empleo de aditivos específicos y la optimización del tamaño de partícula. En todo este trabajo se puso de manifiesto igualmente la imposibilidad de emplear materias primas arcillosas o caoliníticas, ya que proporcionaban unas condiciones reológicas que no eran las adecuadas para garantizar un correcto comportamiento durante el proceso de impresión.

Por otra parte, los requerimientos en cuanto al tamaño de partícula de esta incipiente tecnología son mucho menos exigentes que en el caso de la tecnología DOD de alta definición, pudiendo emplear partículas del orden de decenas de micras. Este factor, junto con la ya mencionada imposibilidad de utilizar materias primas arcillosas y caoliníticas, hizo que el desarrollo de las composiciones para conseguir los acabados cerámicos y efectos estéticos deseados se centrara en reformular los esmaltes tradicionales a partir de materias primas y fritas de uso habitual en el sector cerámico.

Una vez ajustada la proporción de fritas y materias primas adecuadas para cada uno de los acabados deseados, se procedió a incorporar pigmentos cerámicos en las composiciones de estos esmaltes base, desarrollando una amplia gama de colores sin que se apreciaran dificultades adicionales que obligaran a realizar modificaciones sustanciales de las composiciones de partida.

\subsection{Decoración de Cerámica Vitrificada: SMART-CID ${ }^{\circledR}$ y DECAL-CID}

\section{SMART-CID ${ }^{\circledR}$ : TINTAS DIGITALES PIGMENTADAS PARA LA DECORACIÓN DE PIEZAS CERÁMICAS CON SUPERFICIES VITRIFICADAS}

Las técnicas de decoración más empleadas en el campo del Tercer Fuego sobre vidriado cocido son la huecografía o decoración por rodillos y la serigrafía, lo que supone una importante limitación frente a las posibilidades estéticas y de proceso que aporta la tecnología digital de inyección.

Es importante destacar que, a diferencia de las baldosas de monococción, en las cuales el esmalte sobre el que se deposita la tinta es poroso y por tanto absorbe la parte líquida de la misma fácilmente, en las piezas cerámicas de Tercer Fuego la superficie se encuentra vitrificada $y$, en consecuencia, dicha parte líquida de la tinta no puede penetrar en ella, lo que entraña una dificultad adicional a la hora de conseguir una buena definición y calidad de imagen. Mientras que con las técnicas convencionales de decoración, como las ya mencionadas serigrafía o huecografía, esta problemática se solventa mediante el empleo de pastas serigráficas con una viscosidad muy elevada y unos disolventes de evaporación muy rápida, la utilización directa de las tintas digitales pigmentadas para la tecnología de inyección DOD de alta definición no es viable ya que las gotas impresas no mantienen su identidad, por lo que no existía hasta el momento en el mercado una solución totalmente satisfactoria para decorar digitalmente piezas vitrificadas de Tercer Fuego.

Ante esta situación, SMART-CID ${ }^{\circledR}$ constituye la solución definitiva a la decoración digital por inyección de tinta de baldosas cerámicas con superficies vitrificadas, puesto que permite, no solo la definición propia de esta tecnología, sino también diseños de elevada intensidad y gama cromática. Gracias a la solución SMART-CID ${ }^{\circledR}$, las posibilidades en cuanto a tipología de producto se amplían enormemente, pudiendo decorar además de las baldosas cocidas habituales 
de Tercer Fuego, otras hasta ahora imposibles de conseguir, como vidriados con fondo de colores oscuros, granilla pulida, porcelánico pulido, etc.

La clave del éxito de las tintas digitales pigmentadas SMART-CID ${ }^{\circledR}$ ha pasado por llevar a cabo una investigación sobre disolventes y aditivos que permitieran que una vez depositada la gota de tinta sobre la superficie vitrificada, ésta mantuviera su forma, consiguiendo con ello la calidad de imagen y definición requeridas. Además, también ha sido necesaria la optimización de los pigmentos cerámicos y el desarrollo de una frita específica, de manera que, con el tamaño de partícula nanométrico requerido para la tecnología de inyección DOD de alta definición, se consiguiera una coloración intensa y una integración de la decoración en la superficie vitrificada. Todo ello se tuvo que compaginar con que las tintas desarrolladas presentaran los valores apropiados de viscosidad y tensión superficial para conseguir un correcto comportamiento en el proceso de impresión, lo que dio lugar a una nueva tipología de tintas completamente distintas de las existentes hasta el momento en el mercado.

\section{DECAL-CID ${ }^{\circledR}$ : CALCAS DIGITALES PARA LA DECORACIÓN DE OBJETOS CERÁMICOS VITRIFICADOS DE GEOMETRÍA COMPLEJA}

En el sector cerámico existen una serie de productos, como es el caso de la vajillería, ciertas piezas especiales, etc. que, por la complejidad de su geometría no era posible decorarlos directamente por medios digitales. Uno de los métodos más habituales empleados para decorar este tipo de productos es la utilización de calcas que a su vez se decoran con técnicas no digitales (serigrafía o huecograbado) y que posteriormente se depositan sobre la superficie vidriada y cocida del producto en cuestión.

El hecho de que las calcas existentes hasta el momento se decoraran mediante técnicas tradicionales limitaba enormemente las posibilidades estéticas. Ante esta situación se ha desarrollado la solución DECAL-CID ${ }^{\circledR}$ consistente en calcas digitales decoradas mediante la tecnología de inyección con tintas pigmentadas. Por tanto, la combinación de DECAL-CID ${ }^{\circledR}$ y las tintas pigmentadas INKCID ${ }^{\circledR}$ representa la solución definitiva que permite aprovechar las posibilidades estéticas y decorativas del sistema digital de decoración por inyección de tinta en los productos que requieren el uso de calcas, como puede ser la vajillería o, en general, cualquier superficie vidriada que tenga un alto relieve o forma compleja.

Para conseguir la solución digital DECAL-CID ${ }^{\circledR}$, se ha trabajado fundamentalmente en los dos siguientes aspectos:

- Desarrollo de una interfase que, aplicada sobre el papel, fuera la responsable de, por una parte, conseguir una correcta integración de las tintas pigmentadas INKCID ${ }^{\circledR}$ en el objeto a decorar tras el proceso de cocción y, por otra, una adecuada definición de la imagen impresa.

- Desarrollo de una laca que proporcionara un film flexible y continuo y que fuera compatible con las tintas pigmentadas, descomponiendo adecuadamente durante la cocción.

Por lo que respecta a la interfase, la composición desarrollada se basa fundamentalmente en disolventes glicólicos y plastificantes para una correcta aplicación y frita para conferirle las propiedades fundentes adecuadas.
Inicialmente se estudió el tamaño de partícula de la frita para tener una micro-rugosidad homogénea que permitiera fijar adecuadamente las gotas de tinta cuando son depositadas y lograr una correcta definición. También fue necesario desarrollar una composición de frita transparente específica para esta aplicación, atendiendo a aspectos como un coeficiente de dilatación térmica acoplado a los vidriados empleados habitualmente en este tipo de productos, una curva de reblandecimiento adaptada a la descomposición de la laca o una completa transparencia y fundencia adecuada para garantizar la total integración en la superficie decorada.

En cuanto a la laca, los requisitos principales que debía cumplir se pueden resumir en los siguientes puntos:

- Compatibilidad química con los disolventes de las tintas pigmentadas $\mathrm{INKCID}^{\circledR}$ de manera que se consiga transferir completamente la decoración.

- Capacidad para formar un film flexible y continuo del conjunto interfase-decoración-laca.

- Correcta descomposición durante la cocción de manera que no queden restos de materia orgánica en la pieza final.

La figura 4 muestra un gráfico obtenido por Análisis Termo-diferencial y Termo-gravimétrico (ATD-TG) de la composición de laca desarrollada en el que se observa que la descomposición es gradual y desaparece completamente en torno a $420^{\circ} \mathrm{C}$ lo que impide que afecte a la decoración y al acabado estético final de la pieza.

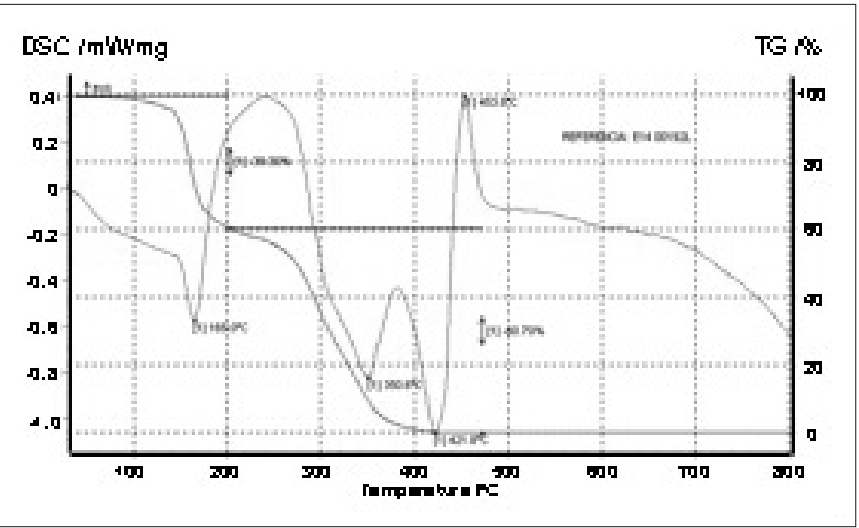

Figura 4. ATD-TG de la laca de las calcas digitales en el que se observa su total descomposición a $420^{\circ} \mathrm{C}$.

Las calcas digitales DECAL-CID ${ }^{\circledR}$ van suponer un cambio radical en la decoración de objetos cerámicos, como es el caso de piezas de vajilla, tejas esmaltadas, listelos con relieve muy pronunciado, etc., aportando a su vez todas las ventajas estéticas y técnicas asociadas a la tecnología de inyección. Todo ello contribuirá a potenciar este nicho de mercado, ya que se podrá disponer de productos más competitivos y con mayor aceptación por parte del usuario final.

\section{CONCLUSIONES}

El conjunto de soluciones digitales por las que la Sociedad Española de Cerámica y Vidrio ha galardonado con el Premio Alfa de Oro $2013^{5}$ a la empresa TORRECID, suponen Novedades Mundiales en el campo de la impresión digital para el sector cerámico que van a proporcionar un 
mayor valor añadido a la cerámica y van a permitir un posicionamiento de liderazgo de este sector frente a otro tipo de materiales

Este premio Alfa de Oro 2013 tiene una especial relevancia puesto que coincide con el $50^{\circ}$ aniversario del GRUPO TORRECID y viene a representar el reconocimiento a 50 años de apuesta continuada por la INNOVACIÓN, después de los cuales la empresa sigue planteándose nuevos sueños y retos para provocar los cambios futuros.

Las diferentes soluciones digitales que el GRUPO TORRECID ha ido incorporando durante estos años en el sector, junto con la posibilidad de emplear los soportes de fino espesor SLIMCID ${ }^{\circledR}$, han provocado un cambio revolucionario en la estética de los productos cerámicos, alcanzando su máxima expresión con STYLE-CID ${ }^{\circledR}$, la Nueva Cerámica con la que la empresa marca las tendencias de futuro.

STYLE-CID ${ }^{\circledR}$, con sus diseños muy elaborados, de gran creatividad y hechos con un gusto exquisito, personaliza la moda cerámica haciéndola Única, Universal y Atemporal. Se trata de una cerámica que se puede aplicar en cualquier espacio, que gusta a todos los mercados y que no pasa de moda, permitiendo crear ambientes que emocionan y despiertan sensaciones.

En definitiva, STYLE-CID ${ }^{\circledR}$ representa no sólo una clara respuesta a los retos actuales, sino que es la nueva puerta hacia el futuro que el GRUPO TORRECID pone a disposición de sus clientes para que puedan competir globalmente con las mejores ventajas competitivas.

\section{BIBLIOGRAFÍA}

1. I. Hutchings (2010) "Impresión por chorro de tinta para la decoración de baldosas: tecnología y oportunidades", QUALICER'10.

2. I quaderni di ACIMAC (2009) "La decorazione digitale di piastrelle ceramiche".

3. J.L.Rodrigo (1996) "Estudio de algunas de las variables que influyen sobre el brillo de vidriados obtenidos a partir de mezclas de frita y óxido de wolframio", QUALICER 94

4. F. Sanmiguel (1998) "Influencia del vidriado base en la desvitrificación de granillas", QUALICER 00.

5. www.secv.es 